\title{
Discrete Time Prey-Predator Model With GENERALIZED HOLLING TYPE INTERACTION
}

\author{
Prodip Roy ${ }^{1}$ and Nabakumar Ghosh ${ }^{2}$ \\ ${ }^{1}$ Department of Mathematics, Mahadevananda Mahavidyalaya, Barrackpore, Kolkata- \\ 120, India. \\ ${ }^{2}$ Department of Mahtematics, Gangapuri Siksha Sadan, Purbaputiary, Kolkata-93, India.
}

\begin{abstract}
We have introduced a discrete time prey-predator model with Generalized Holling type interaction. Stability nature of the fixed points of the model are determined analytically. Phase diagrams are drawn after solving the system numerically. Bifurcation analysis is done with respect to various parameters of the system. It is shown that for modeling of non-chaotic prey predator ecological systems with Generalized Holling type interaction may be more useful for better prediction and analysis.
\end{abstract}

\section{KEYWORDS}

Discrete time model, Generalized Holling type interaction, Bifurcation, Chaotic motion, Stable coexistence.

\section{INTRODUCTION}

Among all mathematical models, prey-predator model have received much attention during the last few decades due to its wide range of application. The dynamic relationship between predators and their preys have long been(and will continue to be) one of the dominant theme due to its universal prevalence and importance. Firstly, the prey-predator interaction model has been described by Lotka[1] and Volterra[2]. After them, more realistic prey-predator model was introduced by Holling[3]. Moreover, there are many different kinds of prey-predator models in mathematical ecology. All the research studies have mainly focused on continuous time preypredator models with differential equations. But sometime the discrete time models governed by difference equations are more appropriate than the continuous time models to describe the preypredator relations. Recent works showed that the dynamics of discrete time prey-predator model is much richer than the continuous time model. Therefore it is reasonable to study discrete time prey-predator models. Again generalization is at the heart of many aspects of ecology, since natural populations are not perfectly homogeneous. Generalized models help us to analyze the influence of the exact mathematical formulation of the functional responses. Therefore the functional responses should be of general type[11] for constructing a real food chain model, since in real world predators of different species may feed on preys in different types of consumption ways.

DOI : $10.5121 /$ ijitmc.2013.1402 
Now study of controlling chaos in dynamical system become an active research area of great attention. Z. Jing and J. Yang[16] discuss the chaotic dynamics of a discrete time predator-prey system. Z. He and X. Jiang[17] study the chaotic behaviour of a discrete dynamical system. T. K. Kar and K. Chakraborty[18] analize the dynamics of a prey-predator model with harvesting tecnique. S. Vaidyanathan[19, 20] successfully designed controller and synchronizer for different hyperchaotic dynamical system.

Now it is very common that scholars[4-10] have a tendency to study the interaction between two species with Holling type functional responses. Danca et al. [12] study the chaotic dynamics in a simple discrete time prey-predator model with Holling type-I relation. Y. H. Fan and W. T. Li[13] establish sufficient conditions for the permanence in a delayed discrete prey-predator model with Holling type-III functional response. Y. G. Sun and S. H. Saker[14] drive a discrete analogy of continuous three level food chain model of Holling type-II response and establish the conditions for the existence of positive periodic solutions with strictly positive components by using continuation theorem in coincidence degree theory. Agiza et al. [15] investigate a discrete time prey-predator model with Holling type-II functional response and analyze the existence and stability of the fixed points. They also calculate the fractal dimension of strange attractor of the model. In the present work, we have introduced a discrete prey-predator model with Generalized Holling type interaction. We discuss the dynamics of the system analytically as well as numerically. Our works showed that this type of model is very useful to describe prey-predator dynamics. Our model is more realistic and the result is very meaningful and different from Agiza et al. [15].

We start by formulating a prey-predator model of Generalized Holling type interaction in sectionIII. In section-IV we are determined the fixed points of our system. The dynamic characteristics of the model are discussed in section-V. Stability nature of the fixed points are fully discussed in section-VI. The results of the system are studied in section-VII using the phase diagrams and bifurcation diagrams with respect to various parameters of the system. Finally the discussion is concluded in section-VIII.

\section{RELATED WORK}

Using actual functional relation is more important in prey-predator model dynamics. If the idea of using generalized functional relation is a new topic, but some meaningful research studies were done on this topic. Gross et al.[11] discuss prey-predator model with the idea of generalized Holling interaction function. B. Sahoo[21] studies a prey-predator model with general Holling type interaction in presence of additional food. Leeuwen et al.[22] study an ecological model with a generalized functional response for predators. Su et al.[23] investigate the dynamic complexities of a predator-prey model with generalized Holling type III functional response.

\section{THE MODEL}

The classical prey-predator model with Holling type interaction is as follows:

$$
\begin{aligned}
& \frac{d x}{d t}=a x(1-x)-\alpha \frac{b x y}{1+c x} \\
& \frac{d y}{d t}=\frac{b x y}{1+c x}-\beta y
\end{aligned}
$$




$$
\mathrm{x}(0)>0, \mathrm{y}(0)>0
$$

where $\mathrm{x}, \mathrm{y}$ represent the prey and predator density respectively; a, b, c are the positive parameters that stand for prey intrinsic growth parameter, half saturation parameter, limitation of the growth velocity of the predator population with increase in the number of prey respectively; and $\alpha, \beta>0$ are the conversion and predator's death rate respectively.

Now to understand the complex dynamics of prey-predator relations, we propose the following discrete time prey-predator model with Generalized Holling type interactions:

$$
\begin{aligned}
& x_{n+1}=a_{n}\left(1-x_{n}\right)-\frac{b x_{n}{ }^{p} y_{n}}{1+c x_{n}{ }^{p}} \\
& y_{n+1}=\frac{d x_{n}{ }^{p} y_{n}}{1+c x_{n}^{p}}-\beta y_{n}, p>0
\end{aligned}
$$

where $a, b, c, d, \beta$ are the non-negative parameters.

\section{Fixed Point Of The Model}

Fixed points of the system are determined by solving the following non-linear system of equations:

$$
\begin{aligned}
& x=a x(1-x)-\frac{b x^{p} y}{1+c x^{p}} \\
& y=\frac{d x^{p} y}{1+c x^{p}}-\beta y
\end{aligned}
$$

By simple calculation, we get three non-negative fixed points as follows:

(i) $\mathrm{E}_{0}(0,0)$ is origin,

(ii) $\quad \mathrm{E}_{1}\left(\frac{\mathrm{a}-1}{\mathrm{a}}, 0\right)$ is the axial fixed point in the absence of predator $(\mathrm{y}=0)$ exists for $\mathrm{a}>1$, and

(iii) $\quad \mathrm{E}_{2}\left(\mathrm{x}^{*}, \mathrm{y}^{*}\right)$ is the interior fixed point, where

$$
\begin{aligned}
& \mathrm{x}^{*}=\frac{(1+\beta)_{\mathrm{p}}^{\frac{1}{2}}}{\{\mathrm{~d}-\mathrm{c}(1+\beta)\}_{\mathrm{p}}^{\frac{1}{p}}} \\
& \mathrm{y}^{*}=\frac{\mathrm{d}}{\mathrm{b}} \frac{(1+\beta)^{\frac{1-\mathrm{p}}{\mathrm{p}}}}{\{\mathrm{d}-\mathrm{c}(1+\beta)\}_{\mathrm{p}}^{\frac{1}{2}}}\left[(\mathrm{a}-1)-\frac{\mathrm{a}(1+\beta)_{\mathrm{p}}^{\frac{1}{-}}}{\{\mathrm{d}-\mathrm{c}(1+\beta)\}_{\mathrm{p}}^{-}}\right] \\
& \text {exists if and only if } \mathrm{d}>(1+\beta)\left[\mathrm{c}+\left(\frac{\mathrm{a}}{\mathrm{a}-1}\right)^{\mathrm{p}} .\right.
\end{aligned}
$$




\section{Dynamic Behaviour Of The Model}

The Jacobian matrix of the model at the state variable is given by-

$J(x, y)=\left(\begin{array}{ll}A_{11} & A_{12} \\ A_{21} & A_{22}\end{array}\right)$

Where

$$
\begin{aligned}
& A_{11}=a(1-2 x)-\frac{b y p x^{p-1}}{\left(1+c x^{p}\right)^{2}} \\
& A_{12}=-\frac{b x^{p}}{1+c x^{p}} \\
& A_{21}=\frac{d y p x^{p-1}}{\left(1+c x^{p}\right)^{2}} \\
& A_{22}=\frac{d x^{p}}{\left(1+c x^{p}\right)}-\beta
\end{aligned}
$$

The characteristic equation of the Jacobian matrix can be written as

$$
\lambda^{2}-\operatorname{Tr} . \mathrm{J}(\mathrm{x}, \mathrm{y}) \cdot \lambda+\operatorname{Det} . \mathrm{J}(\mathrm{x}, \mathrm{y})=0
$$

Where $\operatorname{Tr} . J(x, y)$ is the trace and Det.J(x,y) is the determinant of the Jacobian matrix $J(x, y)$ which is defined as

$\operatorname{Tr} . J(x, y)=a(1-2 x)-\frac{b y p x^{p-1}}{\left(1+c x^{p}\right)^{2}}+\frac{d x^{p}}{\left(1+c x^{p}\right)}-\beta$

and

$\operatorname{Det} . J(x, y)=a(1-2 x)\left[\frac{d x^{p}}{\left(1+c x^{p}\right)}-\beta\right]+\beta \frac{b y p x^{p-1}}{\left(1+c x^{p}\right)^{2}}$

Hence the model is a dissipative dynamical system if

$|\operatorname{Det} . \mathrm{J}(\mathrm{x}, \mathrm{y})|<1$, conservative dynamical system, if and only if $|\operatorname{Det} . \mathrm{J}(\mathrm{x}, \mathrm{y})|=1$, and is an undissipated dynamical system otherwise. 


\section{Stability Of The Fixed Points}

Let $\lambda_{1}$ and $\lambda_{2}$ be the two roots of Equn. (6), which are called eigen values of the fixed point (x, y). A fixed point (x,y) is called a sink if $\left|\lambda_{1}\right|<1$ and $\left|\lambda_{2}\right|<1$, so the sink is locally asymptotically stable. The point ( $x, y)$ is called a source if $\left|\lambda_{1}\right|>1$ and $\left|\lambda_{2}\right|>1$, so the source is locally unstable. The point (x,y) is called a saddle if $\left|\lambda_{1}\right|>1$ and $\left|\lambda_{2}\right|<1$ ( or $\left|\lambda_{1}\right|<1$ and $\left.\left|\lambda_{2}\right|>1\right)$. And the point (x, y) is called non-hyperbolic if either $\left|\lambda_{1}\right|=1$ or $\left|\lambda_{2}\right|=1$.

Now we discuss the stability of the fixed points by the following three Lemma:

6.1. Lemma-1: The fixed point $E_{0}$ is a sink if $a<1$ and $\beta<1$; source if $a>1$ and $\beta>1$; saddle if $\mathrm{a}>1$ and $\beta<1$ (or $\mathrm{a}<1$ and $\beta>1$ ) and non-hyperbolic if $\mathrm{a}=1$ or $\beta=1$.

Proof: The Jacobian matrix at $\mathrm{E}_{0}$ is given by

$$
J\left(E_{0}\right)=\left(\begin{array}{ll}
a & 0 \\
0 & -\beta
\end{array}\right)
$$

Hence the eigen values of matrix $\mathrm{J}\left(\mathrm{E}_{0}\right)$ are $\lambda_{1}=\mathrm{a}$ and $\lambda_{2}=-\beta$. Thus it is clear that the point $\mathrm{E}_{0}$ is a sink if $\mathrm{a}<1$ and $\beta<1$; source if $\mathrm{a}>1$ and $\beta>1$; saddle if $\mathrm{a}>1$ and $\beta<1$ (or $\mathrm{a}<1$ and $\beta>1$ ) and non-hyperbolic if $\mathrm{a}=1$ or $\beta=1$.

6.2. Lemma-2: If a > 1, then for all permissible values of parameters-

(i) $\quad \mathrm{E}_{1}$ is a sink if $1<\mathrm{a}<3$ and

$\mathrm{d}<(1+\beta) \frac{\left[\mathrm{a}^{\mathrm{p}}+\mathrm{c}(\mathrm{a}-1)^{\mathrm{p}}\right]}{(\mathrm{a}-1)^{\mathrm{p}}}$

(ii) $\quad \mathrm{E}_{1}$ is a source if $\mathrm{a}>3$ and

$$
\mathrm{d}<(1+\beta)^{\frac{\left[\mathrm{a}^{\mathrm{p}}+\mathrm{c}(\mathrm{a}-1)^{\mathrm{p}}\right]}{(\mathrm{a}-1)^{\mathrm{p}}}}
$$

(iii) $\mathrm{E}_{1}$ is a non-hyperbolic if $\mathrm{a}=3$ or

$$
\mathrm{d}=(1+\beta)^{\underline{\left[\mathrm{a}^{\mathrm{p}}+\mathrm{c}(\mathrm{a}-1)^{\mathrm{p}}\right]}} \frac{\left.\mathrm{a}^{\mathrm{p}}-1\right)^{\mathrm{p}}}{}
$$

(iv) $E_{1}$ is a saddle for the other values of parameters except those values in (i), (ii) and (iii).

Proof: The Jacobian Matrix $\mathrm{J}(\mathrm{x}, \mathrm{y})$ at $\mathrm{E}_{1}$ is given by 
International Journal of Information Technology, Modeling and Computing (IJITMC) Vol.1,No.4,November 2013

$$
J\left(E_{1}\right)=\left(\begin{array}{ll}
2-a & a_{12} \\
0 & a_{22}
\end{array}\right)
$$

Where,

$$
\begin{aligned}
& a_{12}=-b \frac{(a-1)^{p}}{\left[a^{p}+c(a-1)^{p}\right]} \\
& a_{22}=d \frac{(a-1)^{p}}{\left[a^{p}+c(a-1)^{p}\right]}-\beta
\end{aligned}
$$

Now, the eigen values of the matrix $\mathrm{J}\left(\mathrm{E}_{1}\right)$ are $\lambda_{1}=2-\mathrm{a}$ and $\lambda_{2}=\mathrm{d} \frac{(\mathrm{a}-1)^{\mathrm{p}}}{\left[\mathrm{a}^{\mathrm{p}}+\mathrm{c}(\mathrm{a}-1)^{\mathrm{p}}\right]}-\beta$. Hence it is easy to say that,

$\mathrm{E}_{1}$ is a sink if $1<\mathrm{a}<3$ and $\mathrm{d}<(1+\beta)^{\frac{\left[\mathrm{a}^{\mathrm{p}}+\mathrm{c}(\mathrm{a}-1)^{\mathrm{p}}\right]}{(\mathrm{a}-1)^{\mathrm{p}}}}$

$\mathrm{E}_{1}$ is a source if $\mathrm{a}>3$ and $\mathrm{d}<(1+\beta)^{\frac{\left[\mathrm{a}^{\mathrm{p}}+\mathrm{c}(\mathrm{a}-1)^{\mathrm{p}}\right]}{(\mathrm{a}-1)^{\mathrm{p}}}}$

$\mathrm{E}_{1}$ is a non-hyperbolic if $\mathrm{a}=3$ or

$$
\mathrm{d}=(1+\beta)^{\frac{\left[\mathrm{a}^{\mathrm{p}}+\mathrm{c}(\mathrm{a}-1)^{\mathrm{p}}\right]}{(\mathrm{a}-1)^{\mathrm{p}}}} \text { and }
$$

$E_{1}$ is a saddle for the other values of parameters.

6.3. Lemma-3: When $d>c(1+\beta)$ and $c<\frac{1}{\beta(1+\beta)}$, then the interior fixed point $E_{2}\left(x^{*}, y^{*}\right)$ will be:

(i)a sink if a $<\frac{\mathrm{A}}{\mathrm{B}}$ and $\mathrm{a}>\frac{\mathrm{C}}{\mathrm{D}}$; (ii)a source if $\mathrm{a}>\frac{\mathrm{A}}{\mathrm{B}}$ and $\mathrm{a}<\frac{\mathrm{C}}{\mathrm{D}}$; (iii)a non-hyperbolic if $\mathrm{a}=\frac{\mathrm{A}}{\mathrm{B}}$ and (iv)a saddle if $a>\frac{A}{B}$, where

$$
\begin{aligned}
& A=[2 d+p\{d-c(1+\beta)\}(1+k d)][d-c(1+\beta)]_{p}^{-\frac{1}{p}} \\
& B=[p\{d-c(1+\beta)\}(1+k d)-2 d]\left[\{d-c(1+\beta)\}_{p}^{\frac{1}{2}}-(1+\beta)_{p}^{\frac{1}{p}}\right]+2 d(1+\beta)_{p}^{\frac{1}{-}}
\end{aligned}
$$


International Journal of Information Technology, Modeling and Computing (IJITMC) Vol.1,No.4,November 2013

$$
\begin{aligned}
& \mathrm{C}=[\operatorname{pk}\{\mathrm{d}-\mathrm{c}(1+\beta)\}-1]\{\mathrm{d}-\mathrm{c}(1+\beta)\}_{\mathrm{p}}^{\frac{1}{}} \\
& \mathrm{D}=[\operatorname{pk}\{\mathrm{d}-\mathrm{c}(1+\beta)\}-1]\left[\{\mathrm{d}-\mathrm{c}(1+\beta)\}_{\mathrm{p}}^{\frac{1}{-}}-(1+\beta)_{\mathrm{p}}^{-\frac{1}{2}}\right]+(1+\beta)_{\mathrm{p}}^{\frac{1}{-}}
\end{aligned}
$$

Proof: To prove the above lemma, we use the following theorem:

Theorem: Let $\mathrm{f}(\lambda)=\lambda^{2}-\mathrm{P} \lambda+\mathrm{Q}$. Suppose that $\mathrm{f}(1)>0, \lambda_{1}$ and $\lambda_{2}$ are the two roots of $\mathrm{f}(\lambda)=$ 0.Then,

(i) $\left|\lambda_{1}\right|<1$ and $\left|\lambda_{2}\right|<1$ if and only if $\mathrm{f}(-1)>0$ and $\mathrm{Q}<1$; (ii) $\left|\lambda_{1}\right|<1$ and $\left|\lambda_{2}\right|>1$ (or $\left|\lambda_{1}\right|>1$ and $\left|\lambda_{2}\right|<1$ ) if and only if $\mathrm{f}(-1)<0$; (iii) $\left|\lambda_{1}\right|>1$ and $\left|\lambda_{2}\right|>1$ if and only if $\mathrm{f}(-1)$ $>0$ and $\mathrm{Q}>1$; (iv) $\lambda_{1}=-1$ and $\lambda_{2} \neq 1$ if and only if $\mathrm{f}(-1)=0$ and $\mathrm{P} \neq 0,2$; (v) $\lambda_{1}$ and $\lambda_{2}$ are complex and $\left|\lambda_{1}\right|=\left|\lambda_{2}\right|$ if and only if $P^{2}-4 Q<0$ and $Q=1$.

Now, the Jacobian matrix $\mathrm{J}(\mathrm{x}, \mathrm{y})$ at $\mathrm{E}_{2}$ is given by

$$
J\left(E_{2}\right)=\left(\begin{array}{ll}
a_{11} & a_{12} \\
a_{21} & 1
\end{array}\right)
$$

where,

$a_{11}=a\left[1-\left\{\frac{2(1+\beta)}{d-c(1+\beta)}\right\}_{p}^{\frac{1}{p}}\right]-p\left\{1-\frac{c(1+\beta)}{d}\right\}\left[(a-1)-a\left\{\frac{(1+\beta)}{d-c(1+\beta)}\right\}_{p}^{\frac{1}{2}}\right]$,

$a_{12}=-\frac{b}{d}(1+\beta)$,

$\mathrm{a}_{21}=\frac{\mathrm{p}}{\mathrm{b}}\{\mathrm{d}-\mathrm{c}(1+\beta)\}\left[(\mathrm{a}-1)-\mathrm{a}\left\{\frac{(1+\beta)}{\mathrm{d}-\mathrm{c}(1+\beta)}\right\}_{\mathrm{p}}^{\frac{1}{2}}\right]$

The characteristic equation of the Jacobian matrix $\mathrm{J}\left(\mathrm{E}_{2}\right)$ is

$$
\begin{aligned}
& \lambda^{2}-\left[\mathrm{a}\left\{1-\left\{\frac{2(1+\beta)}{\mathrm{d}-\mathrm{c}(1+\beta)}\right\}_{\mathrm{p}}^{\frac{1}{}}\right\}-\mathrm{p}\left\{1-\frac{\mathrm{c}(1+\beta)}{\mathrm{d}}\right\}\left\{(\mathrm{a}-1)-\mathrm{a}\left\{\frac{(1+\beta)}{\mathrm{d}-\mathrm{c}(1+\beta)}\right\}_{\mathrm{p}}^{\frac{1}{}}\right\}+1\right] \lambda+\left[\mathrm { a } \left\{1-\left\{\frac{2(1+\beta)}{\mathrm{d}-\mathrm{c}(1+\beta)}\right.\right.\right. \\
& \}_{\mathrm{p}}^{\frac{1}{2}}\right\}-\mathrm{p} \beta\{\mathrm{d}-\mathrm{c}(1+\beta)\}\left\{(\mathrm{a}-1)-\mathrm{a}\left\{\frac{(1+\beta)}{\mathrm{d}-\mathrm{c}(1+\beta)}\right\}_{\mathrm{p}}^{\frac{1}{2}}\right\}\right]=0
\end{aligned}
$$

Hence from the above characteristic equation (11) and the Theorem, we can easily proved Lemma-3 with the help of previous discussion. 


\section{RESUlts AND DiscuSSION}

We have solved numerically the system (2). We have choosen $b=3.0, d=3.5$ and $\beta=0.01$. In Figure-1 we draw the phase diagram of the system for different values of Generalized Holling parameter ' $\mathrm{p}$ ' with $\mathrm{a}=3.9$ and $\mathrm{c}=0.32$. For $\mathrm{p}=0.9$ system has chaotic behaviour and the system is chaotic for $p=1.0$ also. Chaos disappears from the system and invariant closed curve appears in system for $p=1.2$. Finally, for $p=1.3$ we observe that phase path approaches to a stable fixed point of the system with time. It will take longer time to reach the fixed point.

In Figure-2 we draw the bifurcation diagram of the predator populations with respect to ' $a$ ' in the range $3.0 \leq 4.0$ for $\mathrm{c}=0.32$. For $\mathrm{p}=0.92$ we observe chaotic orbits and cycles occur alternatively. For $\mathrm{p}=1.0$ chaotic orbits and cycles in the system. For $\mathrm{p}=1.1$ we observe stable dynamics for low values of ' $a$ ' but chaotic orbits and cycles for high values of ' $a$ '. Finally for $p=1.3$ we observe stable dynamics behaviour of the system. Similar results are obtained for prey bifurcation which is not presented here.Therefore for $\mathrm{p}=1.3$ we obtain stable co-existence of prey and predator in the model.

In Figure-3 we draw the bifurcation diagram of the predator populations with respect to ' $c$ ' in the range $0.0 \leq 1.0$ for $\mathrm{a}=3.9$. For $\mathrm{p}=0.95$ we observe existence of chaotic orbits, limit cycles and stable dynamics. For $\mathrm{p}=1.0$ chaotic orbits and stable behaviour are observed for long range of ' $a$ ' values and cyclic behaviour for very short range. For $p=1.1$ we observe cycles of period 10 and 5 , chaotic orbits and stable dynamics. Finally for $\mathrm{p}=1.3$ we observe stable behaviour. Therefore stable co-existence of prey and predators are observed in the model. Therefore for modelling nonchaotic predator prey ecological systems, Generalized Holling interaction may be more useful for better prediction and analysis.
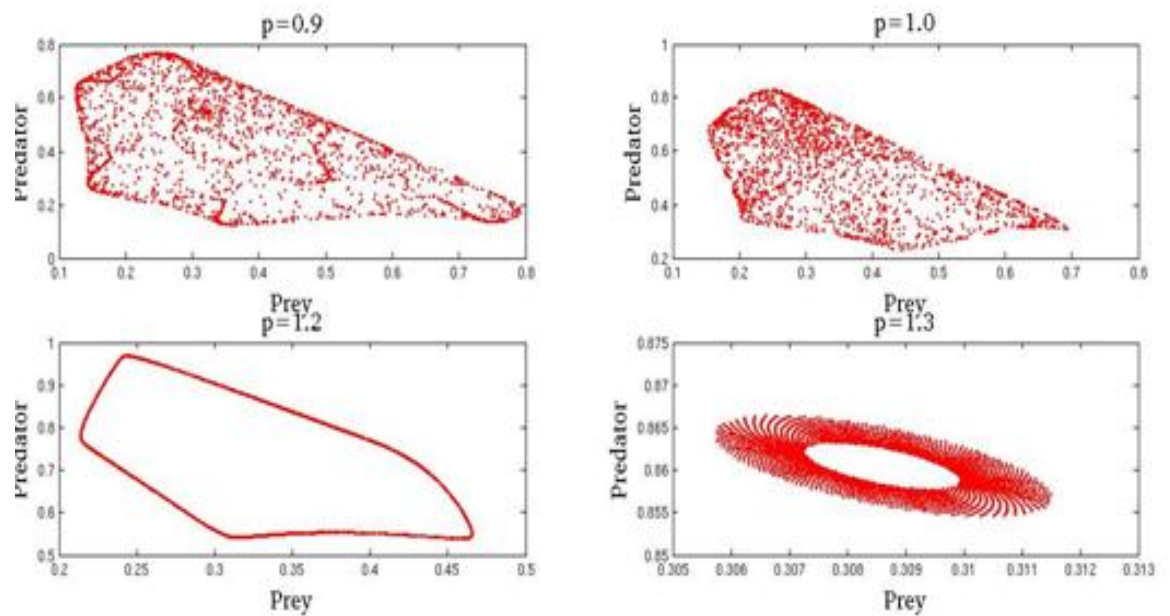

Figure-1:Phase diagram of the system (2) for $\mathrm{p}=0.90, \mathrm{p}=1.0, \mathrm{p}=1.2$, and $\mathrm{p}=1.3$. 

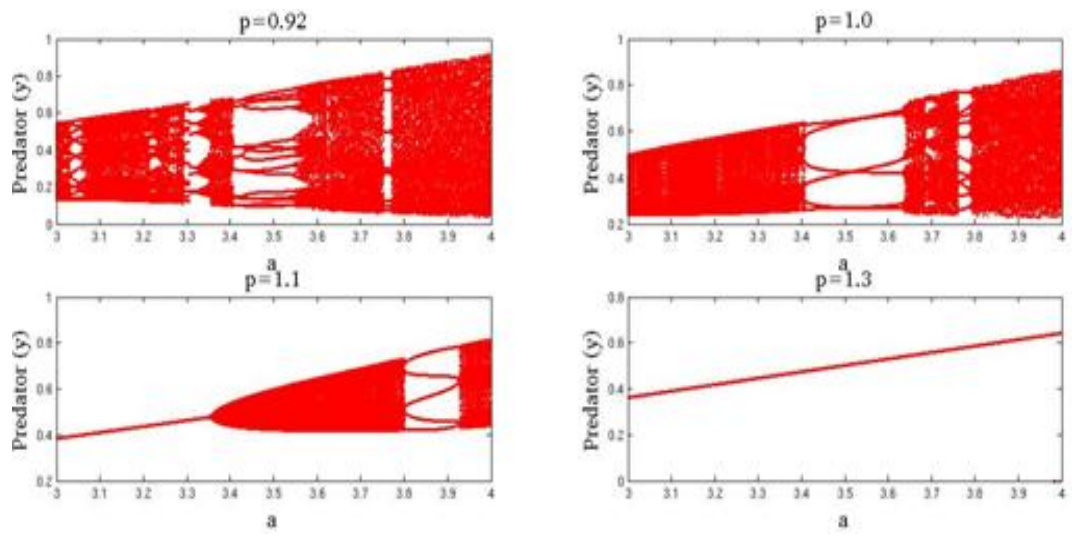

Figure-2: Bifurcation diagram of the predator population with respect to ' $a$ ' varying from 3.0 to 4.0 for $\mathrm{p}=$ $0.92, \mathrm{p}=1.0, \mathrm{p}=1.1$, and $\mathrm{p}=1.3$.
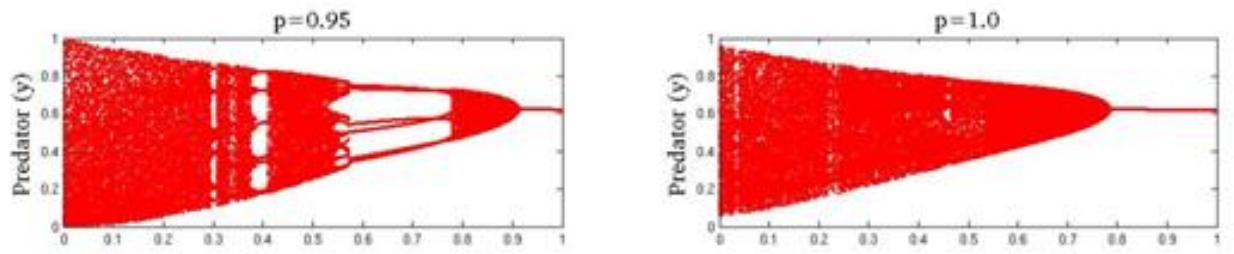

$p=1.1$
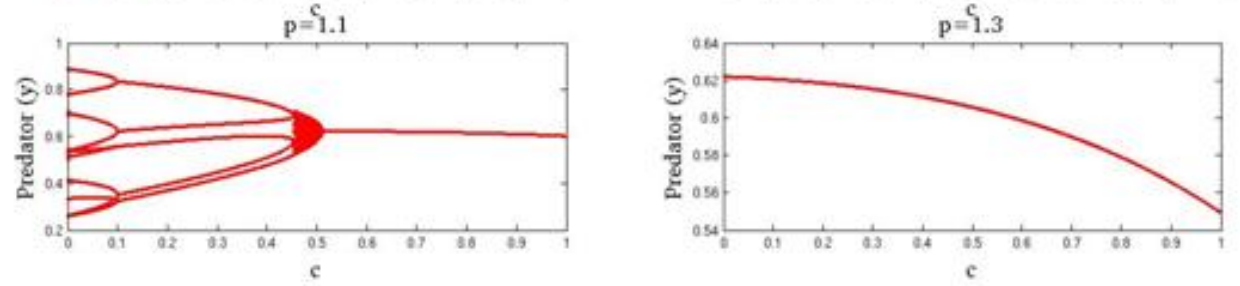

Figure-3: Bifurcation diagram of the predator population with respect to ' $c$ ' varying from 0.0 to 1.0 for $p=$ $0.92, \mathrm{p}=1.0, \mathrm{p}=1.1$, and $\mathrm{p}=1.3$.

\section{CONCLUSIONS}

In the present work, we have introduced a discrete prey-predator model with Generalized Holling interaction. We have find the fixed points of the system and discuss their stability nature analytically. We have drawn phase diagrams and bifurcation diagrams of the system for different values of Generalized Holling parameter. Our model will be very useful for modelling a wide range of predator prey interactions. Modelling of non-chaotic predator prey systems with Generalized Holling interaction may be more useful for better prediction and analysis of a real world ecological systems.

\section{REFERENCES}

[1] Lotka,A.J.(1925) Elements of Physical Biology, Williams \&Wilkins Co., Baltimore.

[2] Volterra,V.(1926), "Fluctuations in the abundance of a species considered mathematically", Nature, 118 , pp. 558-600.

[3] Holling,C.S.(1965)," The functional response of predator to prey density and its role in mimicry and population regulation”, Mem. Ent. Soc. Canada 45 (1965), pp. 1-60. 
International Journal of Information Technology, Modeling and Computing (IJITMC) Vol.1,No.4,November 2013

[4] Ghaziani,R.K.\& Govaerts W.\& Sonck,C.(2012), “ Resonance and bifurcation in a discrete time predator-prey system with Holling functional response", Nonlinear Analysis: Real World Applications 13, pp. 1451-1465.

[5] Fan,M.\& Wang, K.(2002),“ Periodic Solutions of a Discrete Time Nonautonomous Ratio-Dependent Predator-Prey System”, Mathematical and ComputerModelling 35, pp. 951-961.

[6] Su, H.\& Dai,B.\& Chen, Y. \& Li, K. (2008), “ Dynamic complexities of a predator-prey model with generalized Holling type III functional response and impulsive effects", Computers and Mathematics with Applications 56, pp. 1715-1725.

[7] Huang,J.C. \& Xiao,D.M.(2004), “ Analysis of bifurcations and stability in a predator-prey system with Holling type-IV functional response", Acta Math Appl Sinica 2004;20(1), pp. 167-78.

[8] Etoua,R.M.\& Rousseau, C.(2010), “ Bifurcation analysis of a generalized Gause model with prey harvesting and a generalized Holling response function of type III", J. Differential Equations 249 (2010), pp. 2316-2356.

[9] Zhang,W.\& Zhu, D.\& Bi ,P.(2007), “ Multiple positive periodic solutions of a delayed discrete predator-prey system with type IV functional responses", Applied Mathematics Letters 20 (2007), pp. 1031-1038.

[10] Roy,P.\& Sahoo,B.\& Poria, S.(2012), "Seasonal Variation of Carrying Capacity on Diseased Model can Cause Species Extinction”, International Journal of Chaos, Control, Modelling and Simulation (IJCCMS) Vol.1, No.2, December 2012,pp.1-10.

[11] Gross,T.\& Ebenhoh,W.\& Feudel, U.(2004), "Enrichment and foodchain stability: the impact of different forms of predator-prey interaction", J. Theor. Biol., 227, pp. 349-358

[12] Danca,M.\& Codreanu,S.\& Bako, B.(1997), "Detailed analysis of a nonlinear prey-predator model", J. Biol. Phys. 23, pp. 11-20.

[13] Fan,Y.H.\& Li,W.T.(2004),"Permanence for a delayed discrete ratio-dependent predator-prey system with Holling type functional response”, Journal of Mathematical Analysis and Applications, 299(2), pp. 357-374.

[14] Sun,Y.G. \& Saker,S.H.(2006), "Positive periodic solutions of discrete three-level food chain model of Holling type II", Applied Mathematics and Computation 180, pp. 353-365.

[15] Agiza,H.N. \& ELabbasy,E.M. \& EL-Metwally, H. \& Elsadany, A. A. (2009), "Chaotic dynamics of a discrete preypredator model with Holling type II", Nonlinear Analysis: Real World Applications 10, pp.116-129.

[16] Jian,Z.\& Yang,J.(2006), “ Bifurcation and chaos in discrste-time predator-prey system”, Choas, Solitons and Fractal 27, pp. 259-277.

[17] He,Z.\& Jiang, X.(2011), "Bifurcation and chaotic behaviour of a discrete-time variable-territory predator-prey model”, IMA Journal of Applied Mathematics, pp.1-20.

[18] Kar,T.K. \& Chakraborty, K.(2010), "Effort dynamics in a prey-predator model with harvesting", International Journal of Information and System Sciences vol.6, no.3, pp.318-332.

[19] Vaidyanathan,S.(2013), "Adaptive Controller and Synchronizer Design for Hyperchaotic Zhou System with Unknown Parameters", International Journal of Information Technology, Modeling and Computing(IJITMC) vol.1, no.1, pp.18-32.

[20] Vaidyanathan,S.(2013), "Active Controller Design for the Hybrid Synchronization of Hyperchaotic $\mathrm{Xu}$ and Hyperchaotic Li Systems", International Journal of Information Technology, Modeling and Computing(IJITMC) vol.1, no.2, pp.21-35.

[21] Sahoo,B.(2012), “A Predator-Prey Model with General Holling Interactions in Presence of Additional Food", International Journal of Plant Research 2(1), pp.47-50.

[22] Leeuwen,E.Van \& Brannstrom, A. \& Jansen, V. A. A. \& Dieckmann, U. \& Rossberg, A. G.(2013), "A generalized functional response for predators that switch between multiple prey species, Journal of Theoretical Biology 328, pp.89-98.

[23] Su,H.\& Dai, B. \& Chen,Y.\& Li,K.(2008), "Dynamic complexities of a predator-prey model with generalized Holling type III functional response and impulsive effects", Computers and Mathematics with Applications 56, pp.1715-1725. 


\section{AUTHORS}

Mr. Prodip Roy has earned M.Sc Degree in Applied Mathematics from University of Kalyani, West Bengal, India. At present he is working as an Assistant Professor at the Department of Mathematics of Mahadevananda Mahavidyalaya, West Bengal State University, India. He is a member of Calcutta Mathematical Society, Kolkata, India. His research includes Interaction of Prey and Predator, Nature of Discrete System.

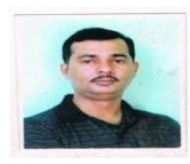

Mr. Nabakumar Ghosh has got M. Sc in Applied mathematics from Calcutta university, West Bengal. India. He has been working as an assistant teacher in the subject of mathematics in Gangapuri Siksha Sadan, Purbaputiary, Kolkata and also a guestlecturer of mathematics in Prafulla Chandra college, Kolkata. He has got Ph.D degree from Visva-Bharati University. 